\title{
Frictional coefficient depending on active friction radius with BPV and BTV in automobile disc braking system
}

\author{
H. P. Khairnar ${ }^{1 *}$, V. M. Phalle ${ }^{2}$, S. S. Mantha ${ }^{3}$ \\ 1,2,3 Department of Mechanical Engineering, Veermata Jijabai Technological Institute, Mumbai, INDIA \\ ${ }^{I}$ Corresponding Author: e-mail: hpkhairnar@vjti.org.in (H.P. Khairnar),mphalle@vjti.org.in (V.M.Phalle), \\ ssmantha@vjti.org.in (S. S. Mantha)Tel+91-022-24198204.
}

\begin{abstract}
The present paper theoretically investigates the behaviour of frictional coefficient considering variants as active friction radius, brake force variation (BPV) and brake torque variation (BTV) in automobile disc brake system. The variations in the frictional coefficient on the piston side of the rotor disc and on the non piston side has been tracked with the use of equations obtained for the disc brake system under equilibrium condition .The effect of parameters like active friction radius, BPV and BTV has been studied as per the computations of the estimation algorithm. The formulated equations were solved by using the input parameters acquired using the braking system and predetermined values. The comparison of estimated frictional coefficient from numerical output is in agreement with vis-à-vis corresponding similar computed from the virtual braking system model in the Simulink. The results indicated that highest frictional coefficient of 0.7 was obtained on the piston side of the rotor disc and active friction radius is predominantly the impact factor for frictional coefficient.
\end{abstract}

Keywords: Automobile, Mechanical, Frictional Coefficient, disc brake, active friction radius, BPV and BTV

DOI: http://dx.doi.org/10.4314/ijest.v9i3.5

\section{Introduction}

The braking system is essential and crucial part of the active safety control of automobiles. Emerging technological developments in the automobiles seek to make precise, effective and secure vehicles. Actuating mechanism of brake caliper can be mechanical, hydraulic or pneumatic against the both the side of the piston as is shown in Figure 1 (Swapnil, 2014). Austin and Michael (2011) stated that when the driver depresses the brake pedal, pistons displacement occures within the vehicle's master cylinder. The master cylinder consists of two pistons in one housing; first is for braking the front wheels, and the second for braking the rear, pressing these pistons enables the movement of the brake fluid through a series of steel and rubber hoses to the car's caliper system. Brake fluid is incompressible; hence the force is transmitted from the master cylinder to another piston system in the caliper.This system pinches the brake pads on both sides of the rotor together resulting in a friction force used to decelerate the vehicle. The brake force can be increased by using the brake pedal as a lever and controlling the piston sizes in the hydraulic system.

After the driver relieves the pressure on the brake pedal, springs in the master cylinder return the pistons back to their initial positions. Due to the return of the pistons, ports in the cylinders' housing are uncovered releasing the pressure that had been built up in the wheel cylinders. A check valve in the system helps to maintain a minimum pressure, hence preventing the inclusion of air in the lines as stated by Austin et al. (2011). When the pressure in the wheel cylinders is reduced, the normal force on the brake pads drops quite significantly, allowing the pads to stick on the disc rotor with a very small friction force. As hydraulic brakes are subjected to the variations in the incompressibility of the hydraulic brake fluid, introducing air can have detrimental effects on the braking reliability and efficiency. Presence of air bubbles in the system can make the brakes feel spongy. This is due to the fact that when the brakes are applied and the pressure in the system increases, the air pockets will compress. This leads in less of the 
brake force being transferred to the wheel cylinder, and hence a less efficient braking system. If air in the form of bubbles has entered the brake system, it must be bled out to prevent the problems discussed earlier. Nouby and Srinivasan (2009) used the eigenvalue analysis combined with DOE to understand the impact of various geometrical parameters on the disc brake squeal phenomenon.

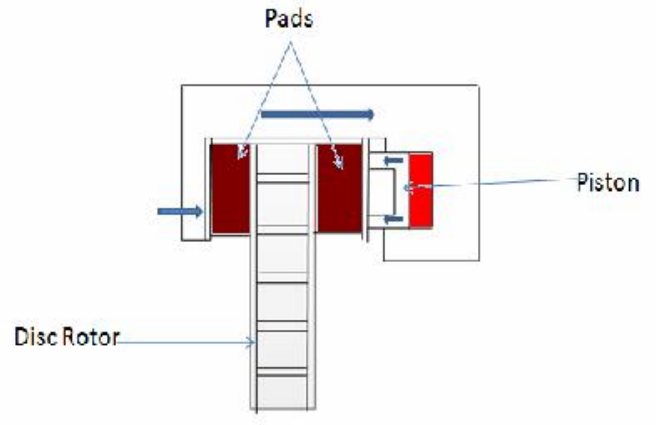

Figure 1. Schematic diagram of Disc brake (Swapnil, 2014)

Eltoukhy and Asfour (2008) concluded that load transfer takes place due to the rearrangement of weight around a vehicle during acceleration, braking, and deceleration. It is pertinent to distinguish between load transfer and weight transfer. Load transfer is an imaginary shift in the weight due to acceleration while the weight transfer takes into consideration the real movement of the vehicle's centre of gravity relative to the wheel axes. .The caliper disc brakes require large actuating force than for drum brakes because they do not have friction moment or servo action to assist the brake application. Circular pads are generally used in caliper brakes which are hydraulically actuated whenever the hydraulic pressure is to be increased by smaller extent as the pads themselves are supported entirely by the piston face.Hence circular pads are less costlier to manufacture since no extra supporting structure is required to be created. Non circular pads are used where the greater performance in regard to pressure expansion is required which is prevalent in aircraft brakes. Ozge, William and Abhijit (2011) evaluated the quality measurements systems in automotive industry and concluded that barking is one of the trouble spots and its effect on the directional stability.

As per Orthwein (2004) coventional design equations for brakes had predicted on either of the assumptions as uniform wear or uniform pressure. If an annular disc brake is replaced with full- faced rigid discs on both input and output shafts and with a lining material that covers the entire face of one of the discs so that $r_{i}=0$, the torque capability of the brake may be given initially by equation

$$
\mathrm{T}=2 / 3 \pi \mu \rho\left(\mathrm{r}_{0}{ }^{3}-\mathrm{r}_{\mathrm{i}}^{3}\right)
$$

An analysis of the force lines by Degestein et al. (2006) along a caliper indicated that the suitable position for the measurement of the clamping and tangential forces can be discovered in the friction surface of the brake pads. Since all forces required for the application of brakes must be supported by the brake pads, with the inclusion of these forces in the back plate of the brake pad, a correct prediction is quite difficult due to the multiple contact points with the caliper.The consideration of the active friction radius on the clamping force due to a stationary brake enables radial shifting to the outer edge of the brake disc. During brake actuation the application of tangential force enables a shifting in the tangential direction. Clamping force is exerted due to the combined effect of hydraulic pressure and the piston surface .The tangential force at the contact of the disc pad and rotor disc is

$$
\begin{array}{cc}
\mathrm{F}_{\mathrm{tP}}=\mathrm{F}_{\mathrm{p}} \cdot \mu & \text { (on friction area of the piston side) } \\
\mathrm{F}_{\text {tnp }}=\mathrm{F}_{\text {np }} \cdot \mu & \text { (on friction area of the non piston side) }
\end{array}
$$

The tangential force, together with mean friction radius $\mathrm{R}$, causes the braking torque,

$$
\text { B.T. }=\left(\mathrm{F}_{\mathrm{tp}}+\mathrm{F}_{\mathrm{tnp}}\right) \cdot \mathrm{R} \text {. }
$$

Ultimately the amount of braking torque results with the help of the dynamic tire radius in the contact patch of the tire, the desired braking force and the deceleration of the vehicle.Due to the support of tangential force on the stator reaction $\left(\mathrm{F}_{1}\right)$ to the piston force results, considering this force $\left(\mathrm{F}_{1}\right)$, the clamping force does not correspond to the piston force during a braking process. Degestein et al. (2006) concluded that uniform surface pressing occurs due to the active friction radius shifting while braking.The caliper expands itself under the high clamping force due to which shifting of the active friction radius occures and a 
bigger active friction radius can be assumed.There are no identical shiftings on piston side and non piston side, since the non piston side has more elasic qualities than piston side with regard to the construction. Han et al.(2014) proposed that variations in the actual and average values of the braking torque are caused due to the deviations between the actual and the nominal geometry of the contact between the brake pads and the disc.

$$
\text { Braking Force }=\int_{-\theta}^{\theta} \int_{R}^{r} F y . \rho v . . R d . R d . \phi
$$

Braking force is transmitted hydraulically through the fluid, for cylinders of the same size force transmitted from one is the similar amount as the force applied to other. By engaging the cylinders of different sizes forces can be increased or reduced allowing users to achieve desired braking force for each wheel

$$
\text { Braking Force }=\int_{-\theta}^{\theta} \int_{R}^{r} F y \cdot \rho v \cdot R^{2} \cdot d R \cdot d \theta
$$

The uniform wear out has been assumed by Jorge (2012) in the brake pads and disc, the braking torque can be calculated as a function of brake inner disc and outer diameter ,the pressure between brake pad and disc and frictional coefficient $(\mu)$ at the contact of pad and disc. To prevent the numerical instabilities, the transition between the positive and negative braking torque should be smooth. Even though wide research work have been carried out in the field of automotive braking system regarding the effect of the frictional coefficient $(\mu)$ at the disc rotor and pad interface on various parameters, but it did not analyze the combined effects of the BPV, BTV and active friction radius at the pad- rotor disc interface.

The present study comprises multitude of equations for frictional coefficient $(\mu)$ obtained under the equilibrium conditions using principles of classical mechanics considering the various longitudinal forces. Influence of the operating parameters such as brake force, brake torque and active friction radius are evaluated. The equations are solved with the predetermined values and reference system data. The computed results are compared with virtual Simulink model of the disc braking system.

\section{Frictional Coefficient with Active Friction Radius, BPV and BTV}

The rotational deceleration of the wheel and disc are based on the torque caused by the force of friction between the brake pad and disc rotor. The friction force responsible for deceleration is a function of the force applied by the driver to the pedal. The combined effect of forces applied on the wheel show that the vehicle speed decreases as the force of the road on the tire overcomes the force of the axle on the wheel. The clamping force $\left(\mathrm{F}_{\mathrm{c}}\right)$ acting normal to the contact surface of the disc and the caliper is balanced by the resulting force $\left(\mathrm{F}_{2}\right)$ to attain the equilibrium condition, tangential force $\left(\mathrm{F}_{\mathrm{tp}}\right)$ is acting the downward as shown in Figure 2. Similarly forces at the non piston side of the disc are acting to maintain the equilibrium in the braking process and to avoid the skidding of the vehicle. But due to the actuation mechanism of the piston at the brake disc, the forces at the piston and non piston side are not equal in magnitude, $\left(\mathrm{F}_{\mathrm{np}}\right)$ is the normal force at the contact of the disc and caliper, $\left(\mathrm{F}_{2}\right)$ is the reaction force and $\left(\mathrm{F}_{\text {tnp }}\right)$ is the tangential force. It is pertinent to note that due to the forces $\left(\mathrm{F}_{1}\right)$ and $\left(\mathrm{F}_{2}\right)$ the piston force does not correspond to the clamping force. Due to this phenomenon, variation in the active friction radius occurs. Equilibrium equations at the rotor disc in the longitudinal direction results

$$
\begin{gathered}
\mathrm{F}_{\mathrm{p}}-\mathrm{F}_{2}=0 \quad(\text { piston side }) \\
\mathrm{F}_{1}-\mathrm{F}_{\mathrm{np}}=0 \quad(\text { non piston side })
\end{gathered}
$$

Weight component $(\mathrm{mg})$ in the downward direction takes into account the accumulated mass of the disc and caliper.Due to the inequality of the forces on the piston and non piston side frictional coefficient $(\mu)$ respectively $\left(\mu_{\mathrm{p}}\right)$ and $\left(\mu_{\mathrm{np}}\right)$ causes the friction forces in the lateral direction

$$
\begin{aligned}
& \mathrm{mg}+\mu_{\mathrm{p}} \cdot \mathrm{F}_{\mathrm{P}}=0\quad \text { (piston side }) \\
& \mathrm{mg}+\mu_{\mathrm{np} .} \cdot \mathrm{F}_{\mathrm{np}}=0 \quad \text { (non piston side) }
\end{aligned}
$$




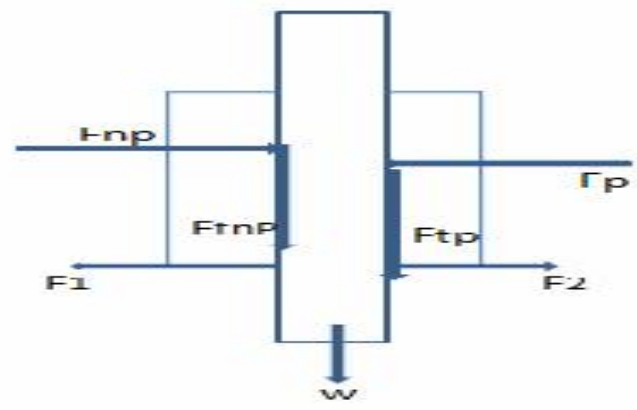

Figure 2:Forces with variations in active friction radius

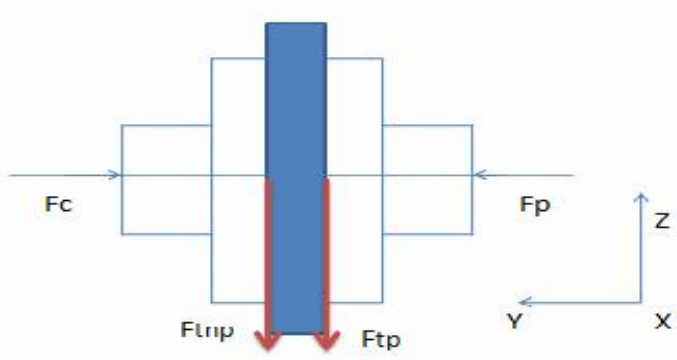

Figure 3. Forces with constant active friction radius.

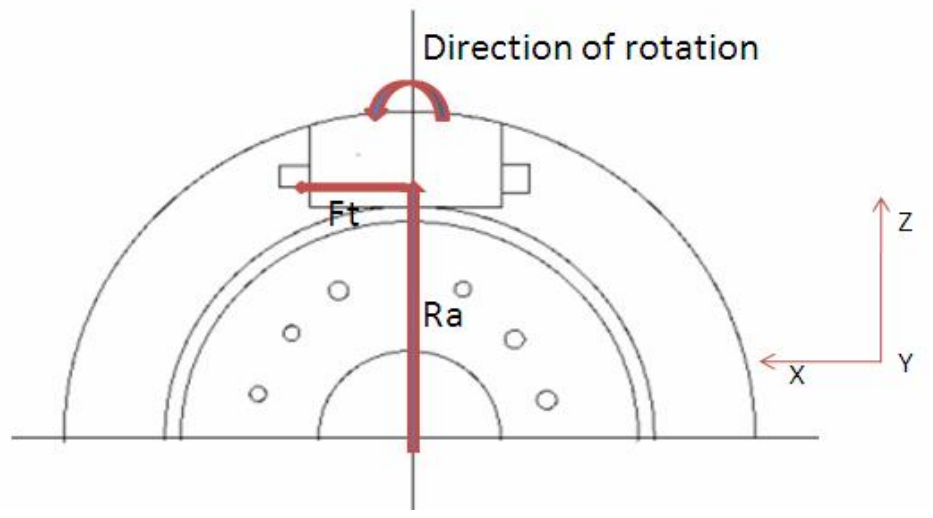

Figure 4. Tangential force at the caliper

The clamping force $(\mathrm{Fc})$ shown in Figure 3 is the result of the pressure exerted by the fluid and the piston surface.The clamping force is responsible for the tangential force $\left(F_{t}\right)$ at the caliper and the disc interface shown in Figure 4 , tangential force $\left(F_{t}\right)$ on piston as well as on the non piston side is expressed below

$$
\mathrm{F}_{\mathrm{t}}=\mathrm{F}_{\mathrm{c}} \cdot\left(\mu_{\mathrm{np}}+\mu_{\mathrm{p}}\right)
$$

The tangential force with the active friction radius $\left(\mathrm{R}_{\mathrm{a}}\right)$ causes the braking torque

$$
\mathrm{T}_{\mathrm{b}}=\mathrm{F}_{\mathrm{t}} \cdot \mathrm{R}_{\mathrm{a}}
$$

The braking torque causes the deceleration of the vehicle, to balance the braking effort required at the front and rear axle torque at the piston and non piston side as calculated below

$$
\begin{array}{cr}
\mathrm{T}_{\mathrm{p}}=\mu_{\mathrm{p}} \mathrm{F}_{\mathrm{p}} \cdot \mathrm{R} & \text { (piston side) } \\
\mathrm{T}_{\mathrm{np}}=\mu_{\mathrm{np}} \mathrm{F}_{\mathrm{np}} \cdot \mathrm{R} & \text { (non piston side) }
\end{array}
$$

Torque increases with the actuation effort, velocity and temperature (Gillespie, 1965).The total braking torque for the front and rear axles takes into account the angle $(\theta)$ for contact patch of the caliper with disc and inner as well as the outer radius.

$$
\mathrm{T}=2 / 3 \mathrm{~F} \cdot \mu \cdot\left(\mathrm{r}_{\mathrm{o}}{ }^{3}-\mathrm{r}_{\mathrm{i}}{ }^{3}\right) \cdot \theta
$$




\section{Operating and Geometric Parameters}

Following Table 1 shows the calculated and referred parameters from the reference vehicle system by Tania et al. (2012).

Table1. Input parameters

\begin{tabular}{cll}
\hline Sr No & \multicolumn{1}{c}{ Parameters } & \multicolumn{1}{c}{ Value } \\
\hline 1. & Input drive force $(\mathrm{lb})$ & 90 \\
2. & Pedal ratio & $4: 1$ \\
3. & Brake pedal force (lb) & 360 \\
4. & Force from master cylinder (psi) & 935.44 \\
5. & Outer radius (in) & 8.2 \\
6. & Inner radius (in) & 4.2 \\
7. & Torque at the rotor (In-lb) & $(0-437289.8)$ \\
8. & Force at the piston and non piston side (lb) & 2644.9 \\
9. & Density of the disc $\left(\mathrm{Kg} / \mathrm{m}^{3}\right)$ & 7850 \\
10. & Density of the friction plate $\left(\mathrm{Kg} / \mathrm{m}^{3}\right)$ & 6000 \\
\hline
\end{tabular}

\section{Frictional Coefficient Estimation Algorithm}

The rotor disc-pad frictional coefficient $(\mu)$ estimation is pertinent for computation of the braking torque, which influence the active safety of the automobiles and the passenger. The estimation algorithm should be of low computational complexity and should present the holistic view of the parametrs involved. Figure 5 shows the flowchart for the frictional coefficient $(\mu)$ computation. This includes two sub parts: one is for estimation of frictional coefficient $(\mu)$ considering the BPV, while the second is for the frictional coefficient $(\mu)$ estimation using the BTV.Since the changes in the active friction radius are responsible for the variations in BPV and BTV, it is considered as the predominant parameter in the estimation of the frictional coefficient $(\mu)$.

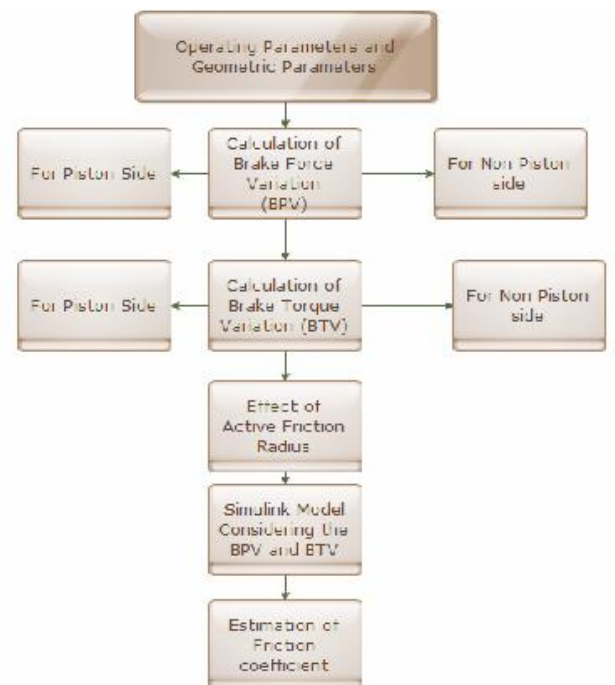

Figure 5. Algorithm for frictional coefficient estimation

\section{Simulink Model for the Braking System}

The virtual model shown in the Figure 6 simulates the dynamics at the disc rotor-pad interface during the brake actuation. It presents a single wheel brake which can be replicated a number of times to represent a model for multi wheel vehicle. The rotor disc is having starting speed corresponding to the vehicle speed before the brake actuation. The slip between vehicle speed and disc speed is taken as constant at 0.8 represented by the constant block paramater.The bang-bang controller used is based upon the actual slip and the desired slip.The control of the brake pressure is considered through a first order lag that represents the delay associated with the hydraulic lines of the brake system. The model then integrates the filtered rate to yield the actual brake pressure. The gain factor for the contact force is fixed at ' 1 '. The calculated brake torque from tangential force and the active friction radus is set as the block parameter. Further the frictional coefficient is computed by ratio of the forces. 


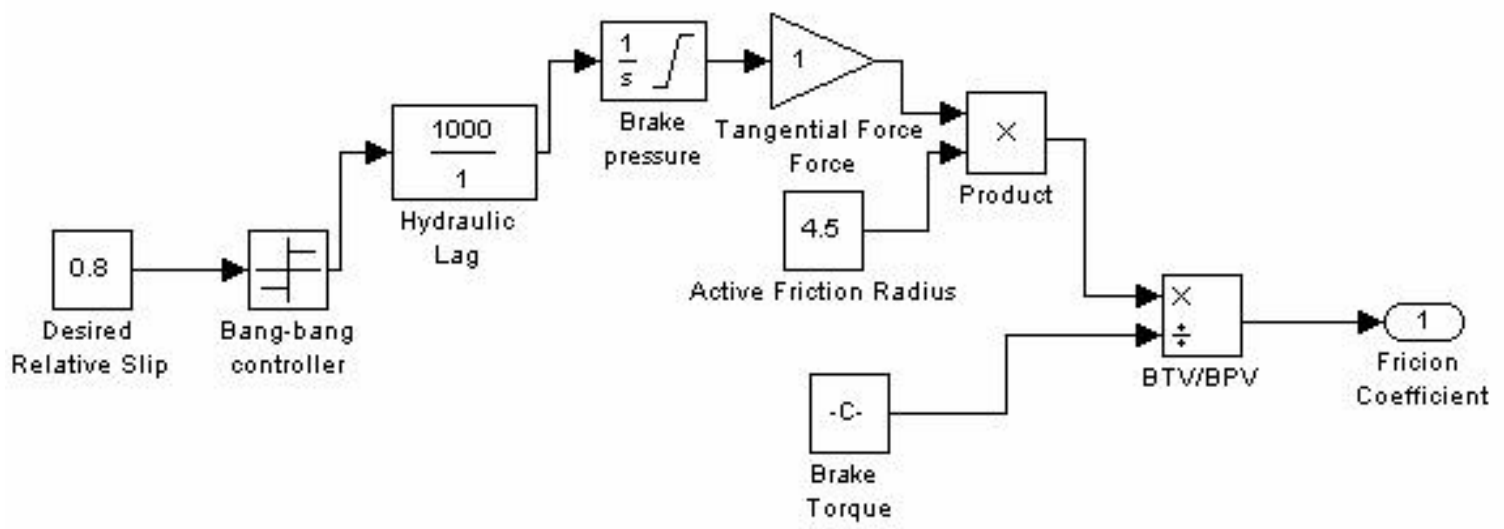

Figure 6. Simulink model for single wheel disc brake.

\section{Validation}

The validation of the presented methodology is based on comparison between computes frictional coefficient $(\mu)$ with the help of output from the formulated equations solved by acquiring data from reference system and frictional coefficient $(\mu)$ obtained from Simulink model of the braking system as shown in Figure 7. Also the, frictional coefficient $(\mu)$ 0.3-0.7 as selected from the database of the simulated results are comprised in the range proposed by Degestein et al.(2006) in published work for manvehicle interface while this investigation concentrates on brake disc rotor-pad inerface.

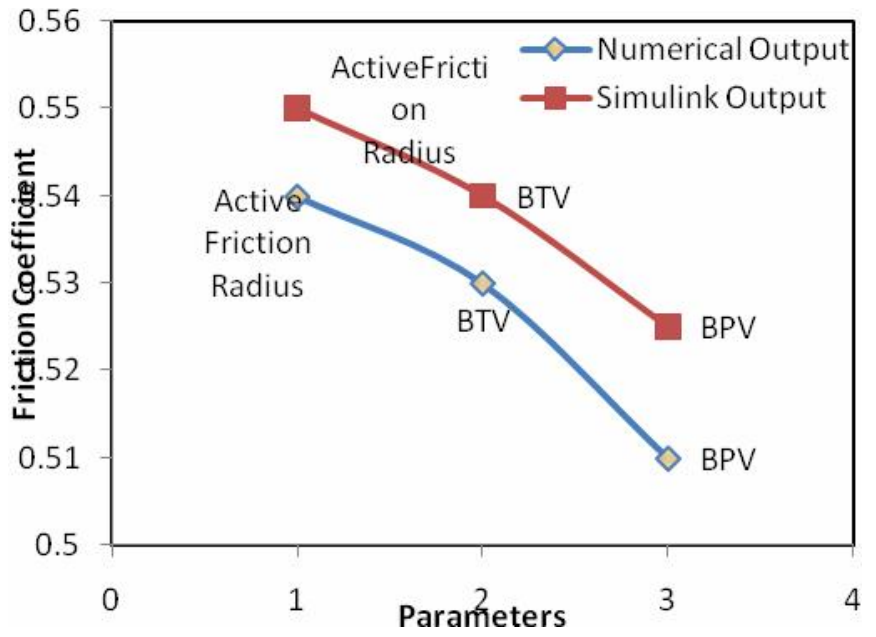

Figure7. Comparison of output for numerical and simulink based estimation

\section{Results and Discussion}

The computed frictional coefficient $(\mu)$ obtained from the numerical simulation of the equations have been discussed below.It depicts the comparison between the frictional coefficient $(\mu)$ obtained for verying conditions input parameters i.e. active friction radius, BTV and BPV.

However the Simulink model can be simulated produce the results as shown in the tables below

Table 2. Torques on the piston side.

\begin{tabular}{ccccc}
\hline \hline Sr.No. & $\boldsymbol{T}_{\boldsymbol{p}}$ & $\boldsymbol{F}_{\boldsymbol{1}}$ & $\boldsymbol{R}$ & $\boldsymbol{\mu}$ \\
\hline \hline 1. & 218644 & 35265.2 & 6 & 0.516 \\
2. & 211355.8 & 34066.18 & 5.8 & 0.534 \\
\hline
\end{tabular}


Table 2 (cont'd). Torques on the piston side.

\begin{tabular}{ccccc}
\hline \hline Sr.No. & $\boldsymbol{T}_{\boldsymbol{p}}$ & $\boldsymbol{F}_{\boldsymbol{1}}$ & $\boldsymbol{R}$ & $\boldsymbol{\mu}$ \\
\hline \hline 3. & 204169.7 & 32907.93 & 5.6 & 0.553 \\
4. & 197227.9 & 31789.06 & 5.4 & 0.574 \\
5. & 190522.2 & 30708.24 & 5.2 & 0.596 \\
6. & 184044.4 & 29664.16 & 5 & 0.620 \\
7. & 177786.9 & 28655.57 & 4.8 & 0.646 \\
8. & 171742.2 & 27681.28 & 4.6 & 0.674 \\
9. & 165902.9 & 26740.12 & 4.4 & 0.705 \\
10. & 160262.2 & 25830.96 & 4.2 & 0.7386 \\
\hline \hline
\end{tabular}

Table 3. Torques on the non piston side.

\begin{tabular}{ccccc}
\hline \hline Sr.No. & $\boldsymbol{T}_{\boldsymbol{N}}$ & $\boldsymbol{F}_{\mathbf{2}}$ & $\boldsymbol{R}$ & $\boldsymbol{\mu}$ \\
\hline \hline 1. & 204169.7 & 32907.93 & 5.5 & 0.564 \\
2. & 211355.8 & 34066.18 & 5.75 & 0.539 \\
3. & 218644 & 35265.2 & 6 & 0.516 \\
4. & 226339.5 & 36506.42 & 6.25 & 0.495 \\
5. & 234305.9 & 37791.32 & 6.5 & 0.476 \\
6. & 242552.7 & 39121.45 & 6.75 & 0.459 \\
7. & 251089.8 & 40498.4 & 7 & 0.442 \\
8. & 259927.3 & 41923.81 & 7.25 & 0.427 \\
9. & 269075.9 & 43399.39 & 7.5 & 0.413 \\
10. & 278546.5 & 44926.9 & 7.75 & 0.4 \\
\hline \hline
\end{tabular}

7.1 Effect of active friction radius on frictional coefficient $(\mu)$

Figure 8(a) shows the output for the frictional coefficient $(\mu)$ produced by the deduced equations for the piston side.The contact point of the coulomb friction force is subjected to variations due to the varying braking effort required to decelerate the vehicle.The results indicates shifting of the active friction radius. The indicated frictional coefficient $(\mu)$ conforms to the range 0.50.7 which is acceptable as per the norms Degestein et al.(2006). The variations in the active friction radius (Ra) ranges from the 4-6 $\mathrm{mm}$. The optimum shifting point can be considered between 5.5-6 mm since it has produced the lesser values of the frictional coefficient $(\mu)$.

The changes in the active friction radius ( $\mathrm{Ra}$ ) leading to changes in frictional coefficient $(\mu)$ for the non piston side are presented in the Figure 8 (b), the changes in the contact point pertains in the range of 5.5-7.5 mm.This range is greater than that respective for the piston side, the assignable cause is the increased braking torque and pressure distribution for piston side.It evident that the prevailing range for active friction radius $(\mathrm{Ra})$ is greater than that for the piston side arising due to unequal force application.
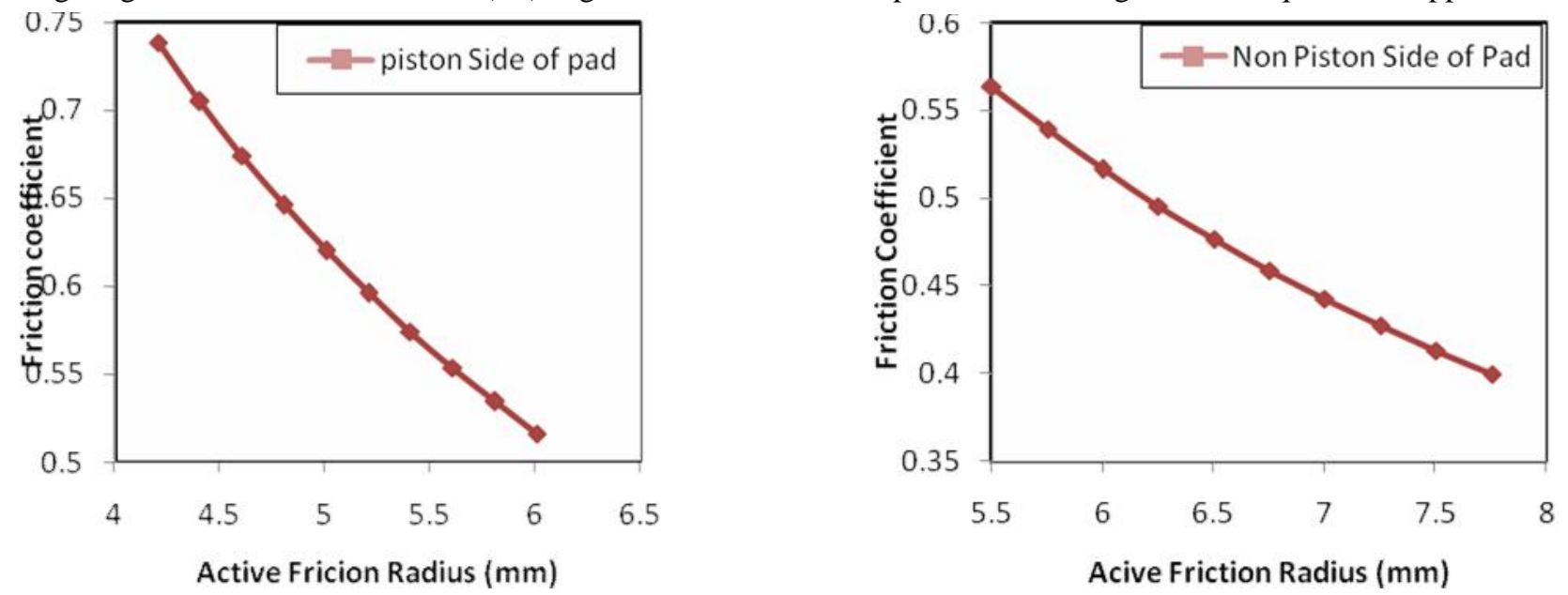

(ब)

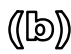

Figure 8. Variation of frictional coefficient with active friction radius

7.2 Effect of radius of friction on Brake Torque Varaition (BTV)

The braking torque variations with respect to the contact point distance of the coulomb friction force are presented in the Figure 9 (a) and (b) respectively for the piston and non piston side.The active friction radius (Ra) variations are ultimately reflected into the 
braking torque variations. The braking torque variations at the piston side are between the 4-6 mm while vis-à-vis silmilar for the non piston side are reflected in the range $5.5-8 \mathrm{~mm}$ which is evident of the probability of less variations of the braking torque at the piston side. Due to the tangential force acting at the interface of the caliper and the disc there is a shift of the contact point distance of the Coulomb friction force primarily because of the movement of the caliper during the braking process. The changes in the active friction radius ( $\mathrm{Ra}$ ) leads to the varitions in the braking torque variations at the brake disc, the torque pulsations are transferred to the axle and ultimately to the suspension systems. Since the forces at the piston side are the result of the hydraulic pressure, the control on the hydraulic pressure and use of abutment means can be helpful to produce the required braking torque at the disc.
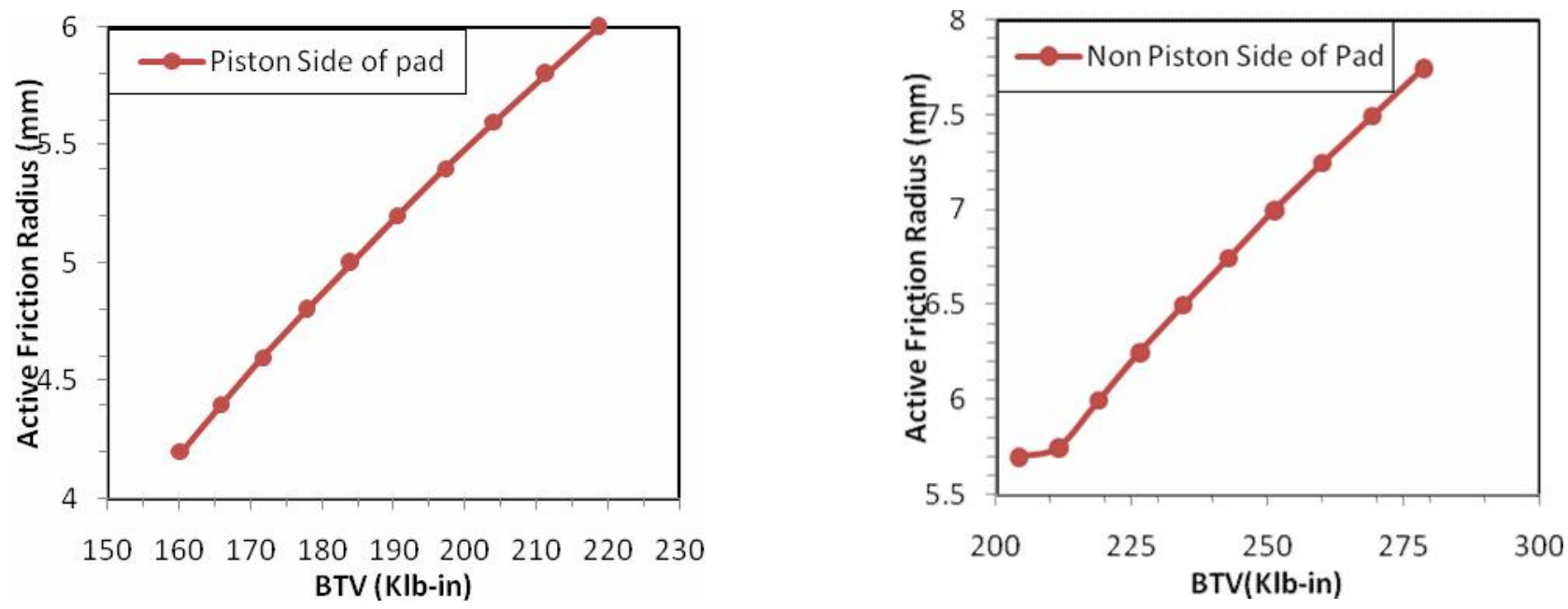

(๑)

(Ъ)

Figure 9. BTV with active friction radius

\subsection{Effect of active friction radius on braking force variation (BPV)}

The effect of tangential force at the interface of the caliper and disc on the active friction radius (Ra) have been studied and indicated in Figure10 (a) and (b) for the piston and non piston side respectively. The force variations for the piston side have been considered in the range of $20-35 \mathrm{Klb}$ produced the changes in the contact point variations between 4-6 mm similarly for the non piston side predetermined force variations of 30-45 Klb enabled the variations of the contact point between 5.5-7.8 mm. The variations in contact point application of the tangential force leads further to the differential wear of the brake pad attached to the caliper which is responsible for the driver discomfort through steering linkage. The tangential force in the forward motion braking is equal to the drag generated by the outer frictional components which will change for the piston and non piston side due to the pressurised fluid on one side of the piston.
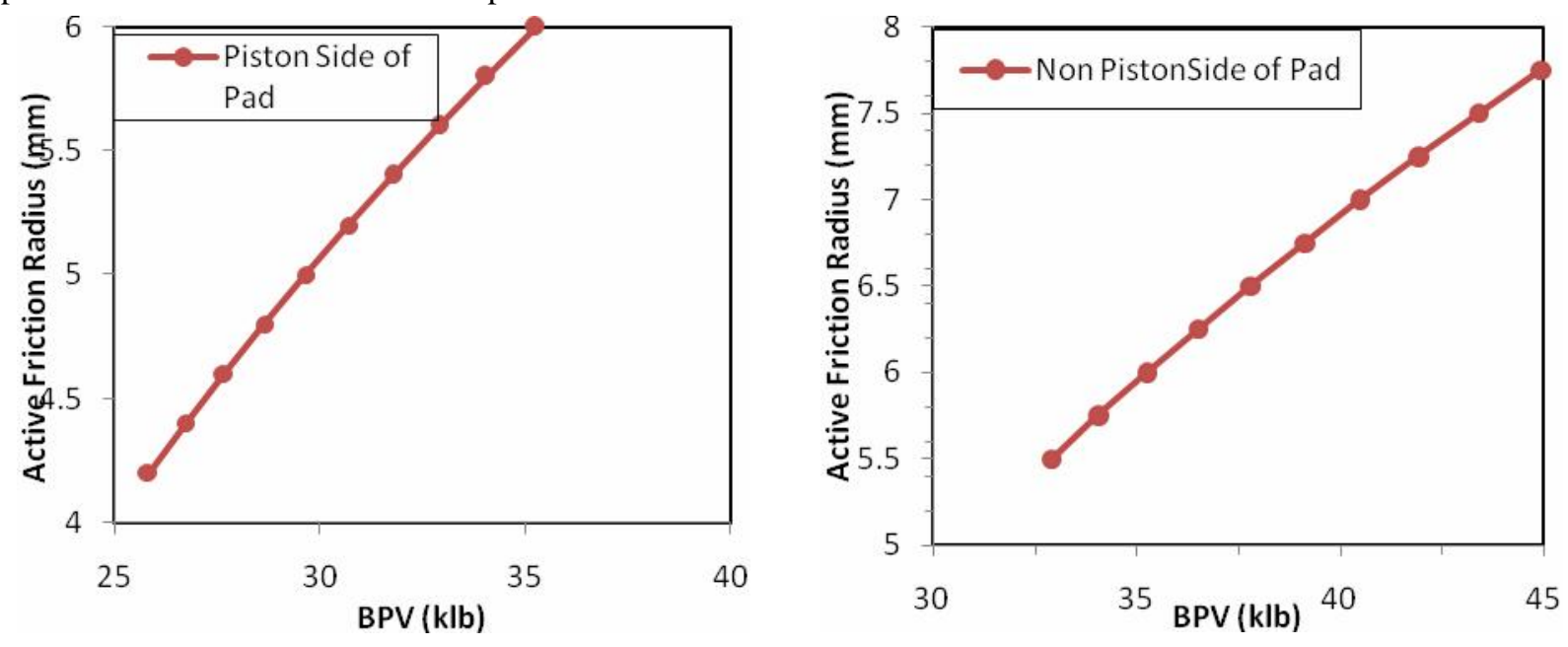

(ब)

(b)

Figure 10. BPV with active friction radius 


\section{Conclusions}

The present investigation reports the computation of frictional coefficient $(\mu)$ at the rotor disc - pad interface considering the BPV and BTV related in the braking process. The brake forces $\left(F_{1}, F_{2}\right)$, braking toques $\left(T_{p}, T_{n p}\right)$ and active friction radius (Ra) were used in the estimation algorithm to compute the frictional coefficient $(\mu)$.Following inferences can be drawn

- The maximum frictional coefficient $(\mu)$ of 0.75 has been indicated for the piston side of the pad as shown in Figure 8 (a) due to the least variations in the active friction radius $(\mathrm{Ra})$.

- As per the simulation results it can be asserted that the frictional coefficient $(\mu)$ algorithm is suitable for estimation of the frictional coefficient $(\mu)$ at the interface of rotor disc -pad.

- The dependence of the BPV and BTV on the active friction radius (Ra) is presented in the Figure 9 (a) and (b), and in the Figure 10 (a) and (b). The increase in active friction radius (Ra) have led to the increase in BPV and BTV as well..

- The state estimation and parameter identification method reported in the paper can accurately predict the state of the braking system and rotor disc - pad interface frictional coefficient $(\mu)$ which will achieve desired safety control.

- The results presented considering various longitudinal forces are useful for automobile brake designers to investigate the phenomenon like brake judder.

\section{Nomenclature}

$\begin{array}{ll}\mathrm{Df} & : \text { Input drive force }(\mathrm{lb}) \\ \mathrm{PR} & : \text { Pedal ratio } \\ \mathrm{Bp} & : \text { Brake pedal force }(\mathrm{lb}) \\ \mathrm{Fm} & : \text { Force from master cylinder }(\mathrm{lb}) \\ \mathrm{r}_{\mathrm{o}} & : \text { Outer radius (in) } \\ \mathrm{r}_{\mathrm{i}} & : \text { Inner radius (in) } \\ \mathrm{T}_{\mathrm{b}} & : \text { Torque at the rotor (in- } \mathrm{lb}) \\ \mathrm{F}_{1} \mathrm{~F}_{2} & : \text { Force at the piston and non piston side }(\mathrm{lb}) \\ \rho & : \text { Density of the disc }\left(\mathrm{kg} / \mathrm{m}^{3}\right) \\ \rho_{\mathrm{f}} & : \text { Density of the friction plate }\left(\mathrm{kg} / \mathrm{m}^{3}\right) \\ \mathrm{F}_{\mathrm{P}} & : \text { Force on Piston side }(\mathrm{lb}) \\ \mathrm{F}_{\mathrm{np}} & : \text { Force on non-Piston side }(\mathrm{lb}) \\ \mathrm{F}_{\mathrm{c}} & : \text { Caliper Force (lb) } \\ \mathrm{F}_{\mathrm{t}} & : \text { Tangential Force }(\mathrm{lb}) \\ \mathrm{R}_{\mathrm{a}} & : \text { Active Friction Radius (cm) } \\ \mu_{\mathrm{p}} & : \text { Frictional coefficient on piston side } \\ \mu_{\mathrm{n}} & : \text { Frictional coefficient on non piston side } \\ \mathrm{T}_{\mathrm{p}} & : \text { Torque on piston side (in-lb) } \\ \mathrm{T}_{\mathrm{np}} & : \text { Torque on non piston side (in-lb) }\end{array}$

\section{References}

Abd R, Abu B and Huajiang O. 2005.Prediction of disc brake contact pressure distributions by finite element analysis. Jurnal Teknologi., Vol. 43 (A), pp. 21-36.

Blau P. J., 2001.Compositions, Functions, and Testing of friction brake materials and their additives. Oak Ridge National Laboratory, ORNL/TM-2001/64,pp.1-38.

Burton R A, Kilaparti S R and Nerlikar V., 1973.A limiting stationary configuration with partially contacting surfaces. Wear, Vol. 24, pp.199-206.

CarreJ. J., Thioux A., Mery J.C., 1986.Disc Brake with Sliding Caliper.US4630713 A.

Cueva G., Sinatora A., Guesser W L.,Tschiptschin A. P.,2003.Wear resistance of cast irons used in brake disc rotors. Wear, Vol. 255, pp.1256-1260.

Degestein, Thomas, Winner, Hermann, 2006. Dynamic measurement of the forces in the friction area of a disc brake during braking process. Institute of Automotive Engineering Department at technischeUniversitat Darmstadt. F2006V218.

Eltoukhy M. and Asfour S., 2008.Braking process in automobiles: Investigation of the thermoelastic instability phenomenon. Modelling and Simulation.I-Tech Education and publishing.ISBN: 978-3-902613-25-7.

Giri N K., 1990.Automotive Mechanics. $2^{\text {nd }}$ edn, Khanna Publisher New Delhi.

Gillspie T.D. 1965.Fundamentals of Vehicle Dyanamics.Society of Automotive Engineers. 294 p.

Han S., Guo, Rui, Cai Y., Tian X., 2014.Disc Break equal analysis of Car. International Conference on Computer, Communications and Information Technology, China North China institute of Aerospace Engineering, China. 
Hohmann C., Schiner K., Oerter K, Reese H.,1999.Contact analysis for drum brakes and disk brakes using.Computers and Structures, Vol. 72, pp.185-198.

Jorge G.F., 2012.A Vehicle Dynamics model for driving simulators. Chalmers University of Technology, Department of Applied Mechanics, Sweden.

Junzo T., Kazuhiro D., Tadashi T., 2000. Prediction of contact pressure of disc brake pad, Technical Notes/JSAE Review, Vol. 21, pp.133-141.

Maleque M. A, Dyuti, Rahman M., 2010.Material Selection method in design of automotive brake disc. Proceedings of theWorldCongressonEngineering. London, Vol III, pp. 1-5.

Nouby M., Mathivanan D., Srinivasan K, 2009. A combined approach of complex eigenvalue analysis and design of experiments (DOE) to study disc brake squeal. International Journal of Engineering, Science and Technology, Vol. 1, No. 1, pp. $254-271$.

OmkarV, Joshi A., Pereira S., 2014. A review on design of hydraulic disc brakes and calculations. International Journal of Scientific Research.Vol.3, pp.161-163.

OrthweinW.C.,2004. Clutches and Brakes Design and Selection. Marcell Dekker Inc.Second Edition.ISBN: 0-8247-4876-X

Senoz O., Daughton W., Gosavi A., Cudney E., 2011. An evaluation of professional quality measurement systems for the automotive industry. International Journal of Engineering, Science and Technology Vol. 3, No. 7, pp. 101-108.

Swapnil R. A., BhaskarD.P. Feb.2014.Design and analysis of disc brake. International Journal of Engineering Trends And Technology.Vol. 8, No. 4

Tania M., Ortiz M., Liaz M. Cardona G., Ramon T., 2012. Design of brake disc, University Of PuretoRico Mayaguez Campus.

Vladuslav B., Moiodraag S., 2007.Mathematical And Simulink model of the pneumatic system with bridging of the dual action cylinder chambers, Vol.5,No.1,pp.23-31.

Wagh N.P., 2005. Design and Analysis of Modular Caliper Assembly.Wichita State University.85 p.

Zhuan L., Xiao P. X., Xiang, Zhu S., 2008.Tribological characteristics of C/C-SiC braking composites under dry and wet conditions. Transactions of Nonferrous materials society of china, pp.1071-1075.

\section{Biographical notes}

Dr.Shankar S.Mantha: An eminent academician and an able administrator. After obtaining engineering degree he did M.E. at VJTI. His Ph.D. research pertained to the area of "Combustion Modeling". His passion for developing the IT solutions for the transperancy in government and speedy approval process vindicated in the projects for the state of Maharashtra, and Municipal Corporations. His stint at All India Council for Technical education (Country's leading regulatory body for engineering colleges) since March 2009 as Vice-Chairman and August 2009 as Chairman was an attempt to expedite the process of approvals an enabling accountability. He has more than 175 publications in international journals and conferences to his credit and 23 Ph.D students who have completed their Ph.D under him.

Dr.Vikas M.Phalle: Born in 1971, obtained his M.E. degree from VJTI an esteemed technical institute, he further continued his education for Ph.D at IIT Roorkee pertaining to the area "performance Analysis of Fluid Film Journal Bearing". His teaching experience is 20 yrs, his research work has been recognized at international level with more than 29 research paper in reputed and high impact factor international and national Journals. Recently he presented paper at 68 th STLE Annual Meeting at Dettroit, USA, 2013.

Hrishikesh P. Khairnar: Research Scholar and Faculty at VJTI. Born in 1977, pursued Master degree in engineering at VJTI in 2005 and joined VJTI as faculty in 2008. His teaching experience covered the subjects of Mechatronics, Measurement at bachelor level and Design of power transmission systems at Masters level. Currently pursuing Ph.D in the area of "Automotive brakes" since 2012.

Received April 2015

Accepted December 2016

Final acceptance in revised form June 2017 